\title{
Interdisciplinary in Promoting Improvements in the Quality of Undergraduate Education in Clinical Nursing
}

\author{
Diana Paula de Souza Rego Pinto Carvalho', Anna Lúcia Dantas', \\ Anna Larissa de Castro Rego ${ }^{1}$, Gabriela Assunção da Costa Mafra Souza ${ }^{1}$, \\ Isabelle Campos de Azevedo', Giovanna Karinny Pereira Cruz ${ }^{1}$, \\ Priscila Fernandes Meireles ${ }^{1}$, Allyne Forte Vitor ${ }^{1}$, Maria Lúcia Ivo², \\ Marcos Antonio Ferreira Júnior ${ }^{1}$ \\ ${ }^{1}$ Departamento de Enfermagem, Universidade Federal do Rio Grande do Norte, Natal, Brasil
${ }^{2}$ Departamento de Enfermagem, Universidade Federal do Mato Grosso do Sul, Campo Grande, Brasil
Email: diana-rego@hotmail.com
}

Received 21 August 2015; accepted 9 October 2015; published 13 October 2015

Copyright (C) 2015 by authors and Scientific Research Publishing Inc.

This work is licensed under the Creative Commons Attribution International License (CC BY). http://creativecommons.org/licenses/by/4.0/

(c) (i) Open Access

\section{Abstract}

The university monitoring is an auxiliary activity of educational support offered to students interested in deepening content and solving questions about the topics learned in the classroom, as well as an opportunity for the development in the student-monitor relationship next to the teaching practice. This study aimed to report the experience lived by the student-monitors linked to monitoring project entitled "Interdisciplinary for improving the quality of education: Physiology, Anatomy and Pathology for Clinical Nursing teaching". It is an experience report experienced by student-monitors linked to the project developed for curriculum component Comprehensive Health Care I, taught in the fifth period of the Undergraduate Nursing course at the Federal University of Rio Grande do Norte, Brazil. This project has four stages: preparation of laboratories and fellows training, construction and application of clinical cases, development of simulations in the laboratory with the students and the final evaluation of the changing process in curriculum practice. The monitoring project has provided contact with a simulation environment for students, for the development of skills and attitudes in solving clinical nursing problems through an innovative approach to integrating disciplinary learning in the classroom and development initiation skills in student-monitors teaching. The approximate relationship with the teacher allows the exchange of knowledge, which makes proactive student-monitor in the very process of teaching and learning, as well as the teacher provides the formation of a more qualified and secure professional for the exercise of appropriate assistance.

How to cite this paper: de Souza Rego Pinto Carvalho, D. P., Dantas, A. L., de Castro Rego, A. L., da Costa Mafra Souza, G. A., de Azevedo, I. C., Cruz, G. K. P., Meireles, P. F., Vitor, A. F., Ivo, M. L., \& Júnior, M. A. F. (2015). Interdisciplinary in Promoting Improvements in the Quality of Undergraduate Education in Clinical Nursing. Creative Education, 6, 1874-1878. 


\section{Keywords}

\section{Monitoring, Learning and Teaching, Clinical Nursing, Interdisciplinary Research}

\section{Introduction}

The university monitoring has been representing an educational support activity offered to students interested in deepening content to solve problems regarding the topics worked in a classroom as well as an opportunity for the development of student-monitor in the initiation to teaching. The monitor is together with the teacher in the teaching-learning process of other students, enhancing their own learning when participating in educational activities (Haag, 2008; Abreu, 2014).

During the practical classes in simulation laboratories usually preceding the activities in practical fields of assistance to human health, the student is subjected to situations of theoretical knowledge to understand and solve the problems encountered in clinical cases studies prepared for this purpose, according to each desired degree of complexity for construction of theoretical knowledge to be applied in practice. At this stage, the teacher leads students to elaborate their own conclusions through a correct clinical reasoning. There are several strategies for teaching, those encouraging student participation, those enabling the exchange of knowledge among them, or those allowing the practice repetition to develop skills (Silveira \& Robazzi, 2011; Guedes et al., 2009).

Monitoring programs give potential and contribute significantly with the student's professional training. These programs are fertile spaces for teaching and learning provided to students, intended to the improvement of the training process by promoting the improvement of teaching quality, and creating conditions for the theoretical study and the development of skills related to teaching activity monitor (Natario \& Santos, 2010).

The monitors in contact with students can capture dimensions of the possible difficulties related to the content or subject as a whole, because this is a student primarily usually of the same course using the same language, and sensitive to problems and feelings that students may face in some specific situations of academic life. At that time, the monitor has an active role and can establish a direct intervention, as soon as they are prepared for it and submit to the teaching difficulties encountered and discussing together the problems in order to strengthen the link between students and the teacher (Natário \& Santos, 2010).

The more active learning, interactivity, participation and immediate feedback are pedagogical advantages found in monitoring projects as strategies to improve the quality of education and promote a significant link in the learning process.

In this context, the aim of this study is to report the experience of the student-monitors linked to the monitoring project "Interdisciplinary for improving the quality of education: Physiology, Anatomy and Pathology for the Clinical Nursing teaching".

\section{Method}

It is an experience report experienced by student-monitors linked to the monitoring project "Interdisciplinary for improving the quality of education: Physiology, Anatomy and Pathology for the Clinical Nursing teaching" developed for curriculum component in Comprehensive Health Care I, taught in the fifth period of the Federal University of Nursing Graduation Course of Rio Grande do Norte (UFRN), Brazil. Such subject deals with issues related to Nursing and Surgical Clinic, in which the monitor works knowledge and skills with a group of students under the Department of Nursing skills laboratories (DENF). The laboratories are equipped with realistic simulation mannequins used for invasive procedures, as well as a structure to simulate actual health care services, providing inputs and various essential equipment for such purpose.

The project was submitted to the Public Notice number 01/2013 entitled "Monitoring Project and Support for Improvement of Undergraduate Education Quality” published by the Undergraduate Dean of UFRN lasting two years (2014 and 2015), approved with grant for the acquisition of materials and equipment, and three monitoring scholarships and two vacancies for volunteer monitors. The project began in January 2014 and has a technical team of students of undergraduate and graduate courses in Nursing and five teacher doctors and masters of DENF.

After approval of the project on the Integrated Action Notice n01/2013 from UFRN, a selection process for 
fellows and monitoring volunteers started. Initially, theoretical and methodological planning was held for the development of the project based on the Education Plan of the subjects under study, prepared by the teaching project coordinator.

The target population of this proposal was students of the above-mentioned subject, having about 100 students/year that would benefit from the project. In addition to the monitors, there was also the physical infrastructure and human resources of DENF/UFRN, specifically teachers and graduate students involved.

The following stages were proposed to achieve the objectives and goals in this study: a) preparation of laboratories and fellows training, b) construction, pre-testing and application of clinical cases, c) development of simulations in the skills laboratory and d) final evaluation of the changing process in curriculum practice.

\section{Results and Discussions}

The practical activities in Nursing laboratories are the essence of student's learning and the proper knowledge of Nursing procedures, certainly reflecting in the performance of other subjects, in their training and consequently in professional life (Silveira, 2011). In this way, to enable the development of the project four stages that structure and permeate the teaching-learning process of the student were proposed, including preparation of clinical cases, training of fellows, and protocols construction to the monitoring.

a) First stage: preparation of laboratories and fellows training

This stage included the training of monitors through an extensive literature review, with thorough reading of content, discussion and practice in DENF skills laboratories. Beyond the theoretical improvement, the monitors were trained about nursing technics by teachers supervisors, according to the Standard Operating Protocols (POP) developed over the years by the subject Comprehensive Healthcare I.

Nursing monitoring is presented as a complement to the learning procedures, to facilitate and awaken creativity and sensitivity of students. This teaching strategy motivates students develop psychomotor skills, since they do not receive only the teachers' information, but they put it into practice. It gives the student confidence and provides assistance based on patient safety and allows the practice of repeatedly techniques on mannequins through simulation, which can prevent or reduce the risk of iatrogenic during supervised practice in real health care services where then, they will be inserted (Silveira, 2011).

Thus, the practical skills laboratory of DENF was organized for the simulations with permanent materials and consumables purchased for the project as well as the use of material already available. The scenarios used to simulate clinical practice, solving simulated cases and teaching activities of the monitoring were essential to the activities established in the project being developed successfully. In this context, it is clear that from the monitoring project, there was a significant improvement in the quality of the proposed activities with the acquisition and disposition of new materials and products for laboratories, in order to contribute to the improvement of technical skills developed by monitors and students.

\section{b) Second stage: construction and application of clinical cases}

Clinical cases were prepared by monitors under the guidance of the teacher coordinator helped by students of the Academic Master's course and Doctoral Nursing, linked to the project. Meetings for the literature review, establishment of clinical skills related to nursing contents taught in the subject Comprehensive Healthcare I, and developing links of content with other subjects involved in the formation of student's clinical reasoning were necessary, as subjects of Anatomy. Physiology and Pathology.

Clinical cases were presented to the discipline's teachers to be evaluated by previous simulations, the adequacy of contents before being presented and applied with students of the fifth semester of the nursing course. The purpose of this teaching method is to encourage the student to develop clinical reasoning before the questioning of the cases, in order to provide opportunity to solve them and strengthen the relationship between theory and practice in the interdisciplinary teaching activities.

\section{c) Third stage: development of simulations in skills laboratories}

The monitors met weekly in the skills laboratories as the theoretical content and their corresponding clinical cases to the pedagogical weeks of the subject Comprehensive Healthcare I. During the monitoring in laboratories, students had access to a clinical case, presented in practice with the idealized skills to that level of education. Then, there was consultation with the simulated patient records for verification of results of laboratory tests that complemented the construction of Nursing Diagnosis and thus the development of clinical reasoning. During the simulation, mannequins and materials were used according to POP instructions. 
Thus, the student is inserted to different situations that simulate the reality and require the development of critical thinking skills, with approach of interdisciplinary knowledge to solving real and potential health problems. It is worth noting the need to use actions that stimulate technical and manual skills, thinking and attitudes/values in teaching and clinical nursing practice (Bittencourt \& Crossetti, 2013).

From this perspective, the monitoring function goes beyond motivation to develop search for knowledge, guiding for critical analysis of theoretical information to be selected and for association with the practice (Abreu, 2014). This process was supervised and monitored by teachers of the subject, making necessary interventions for both achievement of objectives by the students as for the monitors/fellows in training.

The practice of academic monitoring is emphasized as a facilitator of teaching when the monitor promotes the other students clarify curriculum content, guiding study groups and discussions (Silva \& Belo, 2012).

\section{d) Fourth stage: final evaluation of the changing process in curricular practice}

At the end of each Nursing content, evaluation activities were carried out, developed by students and teachers supervisors. This evaluation was through the check-list instrument, referring to the POP of technical skills under discussion.

The exercise in monitoring revealed repercussion in the development of interpersonal relationship, when the student-monitor showed good relationship with their classmates, from the development work in groups, socializing with diverse people, at the time they respected the differences and plurality. Through monitoring, the students approached the teaching experience, with a more realistic view of these activities, when they could see the teacher's role and duties of the angle of those who teach (Silva \& Belo, 2012).

The monitoring project provided students a contact with simulation environment to the development of skills and attitudes in solving clinical nursing problems, through an innovative method of integration in disciplinary learning in the classroom, and development of skills for teaching of the student-monitors, as well as the training of future nurses in a more assertive, motivate and safe way for them and the patient.

Finally, the project evaluated the performance of monitors based on their activities, attendance at meetings, alternative research to develop clinical skills, initiative to develop activities, their role and relationship before the students, teachers and working as a team with other monitors. It also evaluates the development of the project through semi-annual reports to the Graduate Dean of UFRN, studies production for scientific events and preparing articles for publication.

Thus, the monitors develop the role of agent's process of teaching and learning in the relationship with the teacher, based on the analysis and reflection on the educational planning and the classes, relevant actions to the role of teachers (Abreu, 2014).

\section{Final Considerations}

The university monitoring is a strategy used to help encourage the education of teacher training for studentmonitors, as well as facilitate the learning process of the students who participated in this activity. The approximate relationship with the teachers enables the exchange of knowledge, which makes proactive student-monitor in their own process of teaching and learning, and promotes the teacher to train more qualified and reliable professional to exercise proper care.

This project was very important in the development of skills necessary for the proper performance of students-monitors when starting to teach, since they had the theoretical and technical knowledge about the working content and interaction skills with their peers when they organized work environment and the order of events.

Thus, the success of the proposal was evident, making the previous disciplines of Clinical Nursing education in an interdisciplinary way, applicable to the formation of clinical reasoning, to break the traditional disciplinary teaching format currently proposed by most of nursing courses programs in Brazil.

The monitoring project is still not availed by graduate students, especially in the attendance and participation of students during scheduled activities, may be because it is an unfamiliar situation for them. However, it is noteworthy that the monitor-student relationship with their peers facilitates the presentation and discussion of the doubts raised in the classroom.

\section{References}

Abreu, T. O., Spindola, T., Pimente, M. R. A. R., Xavier, M. L., Clos, A. C., \& Barros, A. S. (2014). Academic Monitoring in the Perception of Undergraduate Nursing Students. Revista Enfermagem UERJ, 4, 507-512. 
http://www.facenf.uerj.br/v22n4/v22n4a12.pdf

Bittencourt, G. K. G. D., \& Crossetti, M. G. O. (2013). Critical Thinking Skills in the Nursing Diagnosis Process. Revista Escola de Enfermagem da USP, 47, 341-347. http://www.scielo.br/pdf/reeusp/v47n2/en_10.pdf http://dx.doi.org/10.1590/S0080-62342013000200010

Guedes, G. F., Ohara, C. V. S., Silva, G. T. R., \& Franco, G. R. R. M. (2009). Clinical Teaching in Nursing: The Scientific Production Path. Revista Brasileira Enfermagem, 2, 283-286. http://www.scielo.br/pdf/reben/v62n2/a18v62n2.pdf

Haag, S. G., Kolling V., Silva, E., Melo, S. C. B., \& Pinheiro M. (2008). The Contributions of Monitoring in the TeachingLearning Process in Nursing. Revista Brasileira Enfermagem, 2, 215-220.

http://www.scielo.br/pdf/reben/v61n2/a11v61n2.pdf http://dx.doi.org/10.1590/S0034-71672008000200011

Natário, E. G., \& Santos, A. A. A. (2010). Monitor Program for University Education. Estudos de Psicologia, 27, 355-364. http://www.scielo.br/pdf/estpsi/v27n3/07.pdf http://dx.doi.org/10.1590/S0103-166X2010000300007

Silva, R. N., \& Belo M. L. M. (2012). Experiences and Reflections of Monitoring: Contribution to the Teaching-Learning. Scientia Plena, 8, 1-6. http://www.scientiaplena.org.br/sp/article/view/822/553

Silveira, R. C. P., \& Robazzi, M. L. C. C. (2011). Models and Innovation in Teaching Laboratories in Nursing. Revista de Enfermagem do Centro-Oeste Mineiro, 4, 592-602. http://www.seer.ufsj.edu.br/index.php/recom/article/view/138/247 